\title{
Introduction to A Research Agenda for Urban Tourism
}

\author{
Jan van der Borg
}

\section{Introduction}

Cities not only host more than $50 \%$ of the world's population and are supposed to generate $80 \%$ of all economic growth, they have also become important hubs for global tourism development. Although the attention of travellers on cities as the destinations of their travels already stems from the days of the Grand Tour, most cities missed the explosive growth of tourism demand that started immediately after World War II in the richest parts of the United States and of Europe. In those days, holidays were rather long, concentrated in the summer months, and the main form of transportation was the car. Furthermore, an almost absolute form of relaxation was what holidaymakers were looking for in the 1950s, 1960s and 1970s. As a consequence, the so-called sun, sea \& sand types of holidays were booming. Cities such as London and Paris were important exceptions, as they were not only visited by business travellers, but, possessing unique museums and monuments, also attracted cultural tourists

This started to change dramatically in the 1980s. Holidays became shorter, yet more frequent. The interest in a stronger cultural component in holidays was rising exponentially and tourists became much more active during their vacations. Moreover, air transportation gradually became more accessible, also thanks to the deregulation of aviation from the second half of the 1980s on, which led to the emergence and spectacularly growing importance of low-cost airlines. This mix of changes in tourism demand and supply resulted in an increasing interest in the so-called city-trip, a short, often secondary, holiday with a city as its destination.

At the same time, many cities started to understand that the continuously expanding tourism market offered them concrete possibilities for enlarging their economic bases, which had been eroding rapidly because of deindustrialization. They were now systematically pursuing an active tourism development policy to make themselves more attractive for tourists and inhabitants alike, to 
develop a strong brand that reflects their uniqueness, and to offer additional tourism products, such as events, and invest in the infrastructure that helps tourists easily arrive from and return to their homes. Urban tourism thus grew to become one of the most important segments of the global tourism market.

Urban tourism became such an important segment of the tourism market that academics started studying the phenomenon intensively. Ashworth and Voogd (1990), Law (1993), Van den Berg et al. (1995), and Judd and Fainstein (1999) are some examples of the first publications that contributed to a better understanding of the opportunities that tourism offers for the economic and social development of (especially former industrial) cities. In these publications, the predominant discourse was that of urban tourism as a form of tourism able to help urban economies and societies compensate for the loss of the manufacturing sector, which was relocating to more peripheral areas in search of cheap land or to countries where labour was still cheap, in order to retain competitiveness in a global economy; and that of the population, which was moving towards the suburbs and secondary cities in search of bigger homes and amenities that could not be found in the cities, such as a cleaner environment, and where they could start reinventing themselves (see for example Van den Berg, 1987, and Cheshire and Hay, 1989). Cities such as Baltimore, Lyon, Manchester and Rotterdam were examples for other industrial and port cities to use tourism as a means of diversifying their economic base.

A much less popular discourse in those early studies on urban tourism was concentrating on what can be seen as the flipside of the success of cities in developing themselves as attractions able to capture an important share of the tourism market: overtourism. By simply applying the business model of mass tourism to urban tourism, it has become clear that tourism in cities has the potential to become a, sometimes devastating, force that could suffocate urban economies and societies. This particular discourse can already be found in studies by, among others, Van der Borg (1991), Troitiño Vinuesa (1995), and Costa et al. (1996). Most of the cases studied in this context were smaller South-European heritage cities such as Granada, Coimbra and Venice, which served as case studies to analyse the mechanisms that led to diseconomies and discontent among inhabitants.

The idea that some form of sustainable development path exists for urban destinations as much as for destinations that depend on natural wealth has now finally become mainstream in research. It seems, though, that the current and rather trendy academic attention on overtourism in cities such as Amsterdam, Barcelona, Berlin, Bruges, Dubrovnik, Prague and Venice (see for instance UNWTO, 2019) is dominating the urban research agenda, while the original 
idea that tourism might still be a powerful engine of economic and social development for cities tends to be neglected.

The principal objective of this book on urban tourism is, precisely by trying to find a balance between the two discourses mentioned above, to construct a research agenda that reflects the recent insights that have been gathered on the phenomenon of urban tourism and that helps cities turn tourism into a force that makes them smarter, more sustainable and safer. Twenty-six experts on urban tourism development from all over the world have contributed to this book. They will be sharing their insights in, and experience with, urban tourism from different perspectives. They embrace different disciplines and analyse urban tourism within different geographical contexts. The book thus provides readers with an overview of the issues that have proven to be essential for research in the debate on the role tourism can play in urban development processes. The resulting discourse will be relevant to discussing tourism in cities over the coming years, both from an academic and a policy point of view.

In this first chapter of the book, the phenomenon of sustainable urban tourism is defined, the principal issues regarding urban tourism discussed and the challenges that stem from these issues for research and policy presented. Particular attention will be paid to the link between theory and practice, a common theme in most of the book's chapters. It will furthermore be argued that the COVID-19 crisis - a crisis without precedents in terms of scale and duration - has had a tremendous impact on tourism, changing it permanently, but not fundamentally modifying the principles underlying urban tourism development.

The different chapters of the book are also introduced here and put in context. In the closing chapter, a tentative research agenda for urban tourism will be constructed, very much based on the various suggestions made by the authors who were invited to contribute.

This research agenda not only encapsulates their visions and their views on important research themes, but also includes suggestions for urban tourism policies. It is thus hoped that this book will not only help academics focus their investigations into urban tourism, but also help policymakers implement innovative development policies that transform tourism into an important generator of urban development. 


\title{
Sustainable urban tourism development: definitions, concepts and some theory
}

\author{
According to the UNWTO, Urban Tourism is
}

a type of tourism activity which takes place in an urban space with its inherent attributes characterized by non-agricultural based economy such as administration, manufacturing, trade and services and by being nodal points of transport. Urban/ city destinations offer a broad and heterogeneous range of cultural, architectural, technological, social and natural experiences and products for leisure and business.

This definition, which is rather broad, underlines the complex and diverse nature of urban tourism and links the phenomenon very much to the urban character of the context in which it takes place. In other words, tourism that is staged in urban space is by definition urban tourism, whatever the attractions that urban tourists use during their stay in these places and whatever the motivation that brought them there. Obviously, this territorial approach has some major limitations. It regards visitors to Rio de Janeiro who visit the city to surf, for example, as urban tourists, and makes it difficult to clearly classify excursionism - visiting a city whilst staying in the countryside, as a growing number of urban tourists seem to be doing - as urban tourism. A distinct advantage of this definition, however, is that it may facilitate the generation of straightforward statistics on urban tourism worldwide. More attention will be paid to this issue in the first, conceptual part of the book.

In order to develop a framework in which the evidence gathered through the various cases can be placed and where the innovation in urban tourism research can be presented, it is important to define the concept of sustainable tourism development.

The tourism offer of a destination is complex and composite (see for example Jansen-Verbeke, 1998, and Van den Berg et al., 1995). One of the central components of this offer are the primary tourism products, the attractions a destination offers and that have attracted the people who have decided to visit it. For any particular urban space or city, examples of primary tourism products are monuments, museums, parks and events. These primary products have two important characteristics. The first is that they are unique as they are embedded in a specific socio-economic and environmental context, as all place products tend to be. This uniqueness makes these tourism assets hardly reproducible and therefore extremely scarce. Furthermore, primary tourism products tend to be either public goods or at least goods for which it is hard to exclude specific types of users. This combination of extreme scarcity and 
non-excludability leads to an important challenge: how can we make the best touristic use of these assets? Moreover, and this sometimes becomes an additional complication, the content of the primary tourism products is increasingly less material and more immaterial. In fact, it is often the experience that is generated by visiting a destination that determines its overall quality and, hence, competitiveness (see for instance Pine and Gilmore, 1999, and Richards and Wilson, 2006).

Therefore, the market for primary tourism products does not provide entrepreneurs, visitors and policymakers with a clear and correct price signal embodying the extreme scarcity and the user value that characterize most of them. This absence of a market price, the traditional instrument economists refer to in the case of questions regarding the optimal allocation of assets, and the insistence on a policy that leaves much of tourism development to sheer improvisation, automatically drives destinations to either underutilizing or overutilizing their tourism assets.

In the first case, entrepreneurs, policymakers and tourists do not fully capture the potential value that the assets might have. Entrepreneurs will abstain from investing in tourism development, policymakers will not spend public money on the upgrading of these assets, and tourists will not easily put that destination on their bucket lists. The destination will miss an important part of the obvious opportunities for cultural and socioeconomic development that tourism development might generate. Hence, tourism fails to appropriately sustain the urban destination.

In the case of overutilization, the potential global demand for the destination is infinite, while the tourists only partly perceive how scarce the tourism offer of the destination is. Some tourism firms will use the rent that derives from being located in or close to that destination to premium price the services they offer without sufficiently paying for their privileged position. In addition, many visitors, especially excursionists, do not pay the full price in terms of both the collective costs their visit generates and the user value they derive from the visit. Both the firms and the visitors are freeriding on the destination's assets. This often makes the collective costs much higher than the collective benefits, and again it is easy to argue that this type of tourism development, e.g. overtourism, is not a sustainable form of tourism.

These two rather extreme forms of non-optimal use or of unsustainable tourism development are very widespread. This book will present real-world cases of both under- and overtourism in cities, and important examples of research methods that might be used and of concrete policies that might be 
implemented to make urban tourism development more sustainable. Getting the balance right between appreciating and protecting the tourism assets in urban destinations is far from easy. The aim of this book is to help academics, entrepreneurs and policymakers make urban tourism development more sustainable, fighting the underutilization of urban tourism assets on one hand and over utilization on the other much more effectively.

\section{The structure and contents of this book}

The central part of this book is divided into three different parts.

In the first and rather conceptual part, the market for urban tourism is described, the major tendencies in urban tourism development illustrated and quantified, and the most recent developments of research into the phenomenon are presented.

In the second chapter, by Bozana Zekan and Karl Wöber, with the title "Urban tourism: major trends", the principal characteristics of the market for urban tourism and the major market trends are analysed. They argue that tourism has become a comprehensive, highly diversified and strategically important industry that plays a strong driving role in national economic and social development. Cities have become the key nodes of world tourism development. This chapter focuses on the development of tourism in more than 100 cities in Europe and expounds upon the main trends of world tourism development as reported by European Cities Marketing and the World Tourism Cities Federation, the two leading organizations in the field of city tourism. Regarding the pattern of global tourism development, the share of the European tourism market keeps shrinking, tourism in American cities remains stable and tourism in Asia-Pacific region cities continues to expand under the influence of globalization. For Europe, the underlying causes of the changing nature of city tourism in Europe will be analysed in more detail. Greater global mobility, the information boom and increased knowledge-sharing between people in recent years have facilitated the development of urban structures and led to higher levels of city tourism demand. City tourism services are probably the most highly standardized products compared with other tourism offers and since they became available through online booking engines they are everywhere readily available for purchase. Mainly because of their easy access, cities are ideal destinations for short breaks, which perfectly match general trends in travel behaviour. Many cities have also become more attractive. Cities have constantly developed new products, upgraded their quality of ser- 
vices and enhanced their competitiveness. The "smart city" paradigm, which has been adopted by many cities in Europe, represents an environment where innovation and technology supplement a city's activities and services in order to provide benefits to its residents and visitors. Finally, the growth of meetings and shopping as important travel motivators has substantially supported the growth of city tourism.

The third chapter, "Urban tourism as a special type of cultural tourism", by Greg Richards, poses the question of the extent to which urban tourism can indeed be considered a special form of cultural tourism. Greg observes that Cultural Tourism has always been a key sector of the global tourism market, accounting for just under $40 \%$ of all international travel. Creative tourism is a more recent and smaller niche that has emerged both as a development of cultural tourism, and in opposition to the emergence of "mass cultural tourism". Creative tourism demand is driven by consumers who want more active and participative cultural experiences in which they can use and develop their own creativity. Creative tourism is therefore fed by the general growth in cultural tourism, but at the same time it caters to people who want more out of their cultural experiences. Europe is a well-established market for cultural tourism and cities of art in particular play an important role in all this. European travellers are increasingly interested in discovering new destinations - especially if these offer authentic activities that teach them about local culture. This makes cultural tourism a promising sector for destinations that offer flexible cultural components to appeal to both motivated and incidental cultural tourists. According to Richards, any research agenda for urban tourism should therefore be very closely linked to that for cultural tourism.

The second part of the book focuses on urban tourism in an international comparative perspective. Cases from different continents are discussed and the consequences for the analysis of urban tourism are gathered with an international, comparative perspective. The various cases discussed here are highly representative of the two principal paradigms introduced in the section above: the Croatian art cities with a focus on Split, the Flemish art cities with particular attention on Bruges, Belgium, and Venice, Italy on one hand, and Rotterdam, the Netherlands, and Stockholm, Sweden, on the other. Moreover, in this part some light will also be shone on urban tourism development and policies in African, American and Chinese cities.

In Chapter 4, entitled "Smart governance in historic urban destinations - evidence from Croatia”, Lidija Petrić and Ante Mandić explore several essential smart governance elements and strategies, and the outcomes of an analysis on a sample of Croatian historic cities, both coastal and continental, with 
specific attention on Split, the city known for Diocletian's palace. Additionally, the focus has been made on historic cities facing specific problems related to tourism development as well as to some ecological and institutional issues, considered as contextual factors influencing smart governance. Building on an extensive literature review, an extended version of the smart governance model inaugurated by Bolivar and Meijer (2015) was suggested, to encompass the contextual factors and end with some policy measure proposals. A mixed-method approach was employed to address these issues. First, an importance-performance analysis was conducted to evaluate the cities' mayors or deputies' perception of each of the proposed smart governance categories. Subsequently, a qualitative analysis exploring the cities' strategic documents was conducted to determine progress on smart governance and their development orientation. The research results demonstrate the existence of an importance-performance gap between smart governance categories, with a few of them proving to yield significant impact.

Located in the heart of Europe, the Flemish art cities of Bruges, Antwerp, Ghent, Mechelen and Leuven have seen a steady increase in tourist arrivals and day visitors. Although absolute numbers remain below those of more popular neighbouring urban destinations, such as Amsterdam, Paris or London, growing concern has been raised about the community impact of mass tourism. In Chapter 5, "Understanding community perception through resident attitude studies: a segmentation analysis in Flemish art cities", Bart Neuts and Vincent Nijs argue that, considering the importance of local culture and lifestyle in the attractiveness of the tourism product, a healthy co-integration between resident and visitor is a prerequisite for a successful and liveable destination. In 2017, an initiative was launched to measure resident attitudes towards tourism development through a Weberian lens of formal and substantive rationality. The Resident Empowerment through Tourism Scale (RETS), as originally developed by Boley et al. (2014), was applied within the five main tourism cities, a process that was repeated in 2019. The results allow for generalization, contextualization and a limited time trend. The chapter uses confirmatory factor analysis and structural equation modelling to understand the relations between contributors and distractors for tourism support and provide insight for government actors.

In Chapter 6, Dario Bertocchi and Nicola Camatti present the case of Venice, an iconic example of overtourism, by illustrating the latest developments before the COVID-19 crisis struck its tourism system. In "Tourism in Venice: mapping overtourism and exploring solutions", the authors open their analysis stating that Venice is a tourist destination par excellence. The huge number of visitors that this unique city has hosted each year until 2020 is therefore 
not surprising: the most recent official estimate for 2019 is about 28 million visitors, of which only 5 million are residential tourists who, with an average duration of 2.32 nights, generate almost 12 million overnight stays in registered tourist accommodation. There have been some vicissitudes in visits to Venice in the last few decades, but, excluding 2020, the trend has definitely always been on the rise. As Bertocchi et al. (2020) have shown, it became evident that the number of people visiting Venice has become incompatible with the needs of the city as a whole and that drastic solutions to curb tourism demand are needed. Paradoxically, notwithstanding the drop in the number of visitors, the social distancing measures put in place to fight the COVID-19 pandemic have made the need to decide which share of public space and of public facilities will be dedicated to tourism only more urgent, since they reduce the tourist carrying capacity by almost two-thirds. The chapter starts by presenting updated official statistics on the Venetian tourism phenomenon, with the aim of bringing out the lesson, not yet sufficiently learned by many destinations, that the development of tourism is bound to be inevitably unsustainable if left to improvisation and short-term private interests. Reference will be made to the rather basic concept of the tragedy of the commons, to Butler's theory of the life cycle and to the model of the carrying capacity of a destination. Subsequently, a description will be provided of the development of tourism in Venice since the early 1990s, against the background of global and local changes in the tourism market. In this section the main symptoms of the "Venetianization" of a city of art will be listed and discussed, and several solutions presented to the problems of excessive tourist pressure that Venice has been experiencing for too long and their possible repeatability in other cities trampled by mass cultural tourism.

The seventh chapter, by Shirley Nieuwland, Ewout Versloot and Egbert van der Zee, entitled "The Rotterdam way: a new take on urban tourism management", looks at tourism development in Rotterdam, the Netherlands, a city better known for its port and petrochemical industry than its tourism. While most of the popular urban tourism destinations of North-Western Europe are famed for their historic city centres, a growing number of destinations, such as Rotterdam, challenge the conditionality of having a picturesque historic centre to be a successful tourist destination. Nevertheless, the city of Rotterdam is currently the second largest urban tourism destination in the Netherlands, considering nights spent by tourists. The city is witnessing a transformation from an industrial port city hosting a limited number of visitors into a visitor city with a port. As in other former industrial and port cities, the visitor economy has played an important part in the transformation of Rotterdam. While just decades ago the city was mostly shunned, present day visitors appreciate the diverse and iconic architecture, as well as the creative and 
vibrant atmosphere in which the roughness and edginess actually seem to work in Rotterdam's favour. In fact, Rotterdam made it into Lonely Planet's "best in travel list" of 2016 and is famed in the international media as a "must-visit destination". The city of Rotterdam and its inhabitants are happy that finally their beloved city is acknowledged by others, but at the same time there is a general consensus that the city should not be taken over by tourists. While recent developments make Rotterdam an interesting case study for illustrating how post-industrial cities can reinvent themselves on the basis of the visitor economy and simultaneously become an attractive place to live, work and visit, the present case study aims to go one step further. An important issue here is the question of how to integrate tourism proactively in the diverse landscape of contemporary urban issues and challenges and make tourism work for the city. Empowering marginal socio-economic groups, creating opportunities for local businesses and start-ups, protecting parts of the city from excessive tourism pressure, as well as dealing with the consequences of climate change are among these challenges. The rapid growth in overnight stays during the last six years has become an important reason to create a proactive (tourism) development strategy in which the challenges posed by growing tourism in combination with the broader challenges the city faces are properly addressed.

The starting point for the eighth chapter, "New urban tourism developments in a heritage area. A case study of Skeppsholmsviken 6 in Stockholm, Sweden" by Anna-Paula Jonsson and Tigran Haas, is the observation that the visitor industry is considered a primary industry for Swedish economic growth today. While the industry can bring many benefits in terms of employment opportunities and economic growth, not to mention the cultural benefits of travel, it can also bring unintended consequences of a less desirable nature for a city's population. Commonly cited reasons for increased levels of residents' aggravation vis-à-vis tourism are excessive crowds and decreased access to public space, traffic and infrastructure congestion, increased rental and living costs, crowding out of residential neighbourhoods, commercial transformations geared to target tourists rather than residents and extreme seasonality or peak intensity of visiting crowds. In Stockholm, official strategies and goals for the industry have traditionally focused mainly on quantitative aspects such as the number of arriving visitors, the number of jobs in the visiting sector or the total revenue from the same. Additionally, planners have not considered the visiting industry in their decision making to any considerable extent. It is perhaps for this reason that public strategy documents for Stockholm's tourism development have categorically framed the idea of more visitors as something leading to exclusively positive outcomes. However, as visitor numbers in Stockholm grow, and localized signs of residential discontent start appearing, it is not clear whether the large body of literature on overtourism 
will be able to influence the Stockholm municipality to consider a socially sustainable strategy for the visiting industry in time. By studying an ongoing conflict related to a development project that would attract more visitors to an already over-exploited area in central Stockholm, this chapter aims to explore whether there is potential in the current institutional planning environment to consider, develop and implement a socially sustainable tourist strategy when the visitor industry impacts public space. The chapter employs complementary strategies of qualitative enquiry through interviews, discourse analysis and desk-based research.

In "Urban tourism development in Africa: evidence from Addis Ababa, Ethiopia", Getaneh Addis Tessema and Ephrem Assefa Haile offer some new insights into urban tourism development in the African city of Addis Ababa. They argue that cities in general and African cities in particular offer the distinct advantage of allowing diverse tourist attractions to be visited in a specific location without the need to travel long distances. Historical sites, vibrant cultural practices, sports facilities, shopping centres and business tourism facilities, along with easy access and places to stay, have made cities the centre of attraction. Although urban tourism research dates back to the 1960s, it has disproportionately received meagre attention from scholars. The extant literature on urban tourism is quite fragmented and limited to major cities of the world. There is thus a dearth of urban tourism research in developing countries such as Ethiopia. Addis Ababa is endowed with rich cultural, historical and religious treasures and serves as a gateway for international visitors to the country. It is also the third diplomatic city after New York and Geneva, providing immense opportunity for business tourism. Notwithstanding its untapped potential, the city is not sufficiently benefiting from the tourism sector. There is a dire need for a systematic examination of urban tourism development in the city from a sustainability point of view, taking into account the multi-sectoral, multi-disciplinary and dynamic nature of tourism. The main aim of this chapter is therefore to discuss the nature, challenges and opportunities of urban tourism development in Addis Ababa. To this end, data were gathered using semi-structured interviews and document analysis (from policy documents, statistical bulletins, research outputs, etc.). They were then triangulated to verify the validity of information gathered from different sources, and subsequently coded, described and analysed thematically. The results of the study will serve as input for policymakers, researchers and practitioners in tourism and other fields such as urban planning.

In Chapter 10, titled "Municipal advancement and tourism policy in the United States: economic development and urban restructuring", Costas Spirou gives an overview of urban tourism development in the United States of 
America. Tourism in North America has emerged as a central aspect of cultural policy as cities endeavour to strengthen their existing identities and/or recast new images within the pursuit of economic expansion opportunities. While today urban economic development efforts include culture, leisure and tourism as significant parts of a broader planning mix, urban tourism and related cultural forms did not fit into the schemes for growth during the 1950s and 1960s. Post-World War II urban restructuring was accompanied by a shift from a production-oriented to a consumption-oriented economy. It was within the midst of intercity competition that municipal governments aimed to construct the city of leisure, by the use of various strategies including robust private-public partnerships. The infrastructure that followed in the form of sports stadiums, conventions centres, arenas, museums, parks, concert halls and waterfront developments produced amenities that not only attracted tourists, but also reshaped the socioeconomic realities of residents. In the process, many downtowns were reformulated, giving rise to new neighbourhoods, often causing gentrification and displacement. The chapter examines cities within this broader context while also recognizing the associated complexities and dynamic nature of tourism as a driver of economic advancement and of cultural change.

Xiang Feng, Ben Derudder and Hai Xia Zhou in "Comparative study on Chinese cities as international tourism destinations" (Chapter 11) discuss the challenges that Chinese cities have recently been facing whilst striving for tourism development. The international connectivity of Chinese cities has received much policy and scholarly attention in recent years, and this research agenda is here extended by exploring the position of China's major cities as international tourism hubs. Drawing on the definition of tourism internationalization by Gorcheva (2011), their approach complements earlier research that primarily focused on understanding international tourism activities, market segmentation or spatial distributions by comparing 50 major Chinese cities' "product destination internationalization" with their "business destination internationalization". The results show that, in general, there are broad parallels between both dimensions, with a limited number of cities such as Shanghai, Guangzhou, Beijing or Shenzhen acting as key international tourism hubs in both respects. In spite of these general parallels, there are also some notable differences between some cities, which can be traced back to the often-specific tourism and city development strategies of local governments. They discuss how this study can be used as the starting point for further comparative studies on tourism internationalization in other geographical contexts. 
In the third part of the book, particular attention will be paid to the urban tourism development policies that are designed to make tourism development more effective, more sustainable and safer. The idea here is to start building a toolkit of policies that seem to work, a toolkit for which innovative research forms a strong basis.

The first chapter of this particular part, Chapter 12 of the book, entitled "Overtourism: identifying the underlying causes and tensions in European tourism destinations" is a contribution by Ko Koens and Jeroen Klijs in which they analyse sustainable tourism development policies in cities. They argue that, after a period of relatively uninhibited growth, the discussions on overtourism have again brought to the forefront the inherent tensions that exist between the ways in which local stakeholders use the city compared with tourists and day visitors. The debate on overtourism is rapidly evolving but has so far remained focused largely on single city case studies. This chapter combines research in over 25 European city destinations to provide a thorough overview of the impacts of tourism on city destinations and the extent to which they are seen to lead to overtourism. In doing so, it seeks to highlight developments within and outside tourism that have exacerbated the pressure of tourism on destinations in recent years, and which have led to the relatively sudden outburst of overtourism. It is argued that to fully understand the impacts of tourism and achieve sustainable urban development, it is necessary to better delineate the different ways in which tourism interacts with local developments, be it economically, socially or environmentally. In doing so, the 12th chapter seeks to provide some more clarity on the often implicit and vague notion of sustainable urban tourism.

In their chapter "Is another tourism possible? Shifting discourses in Barcelona's tourism politics", Antonio Paolo Russo, Elsa Soro and Alessandro Scarnato start from the recent experiences gathered on Barcelona, Spain, to argue that urban regimes rely critically on consensus and the normative power of discourse. Tourism is no exception: the development and transformation of contemporary destinations must be understood in relation to discourses of competitiveness, economic buoyancy and community pride, which became hegemonic in society throughout the twentieth century. Yet we are facing a new stage in which pro-tourism discourses face increasing contestation by wider sectors of society. Critical analysis excavating the nexus between discourse, urban regimes and policy developments in the field of tourism is poorly represented in the literature, and especially so when it comes to analysing shifts in the social perception of tourism. The city of Barcelona offers an exceptional context in this respect. The chapter deploys a socio-semiotics approach to reveal how discourses on tourism have been given salience by the 
media during the last four municipal electoral periods in the Catalan capital. The positioning of different urban actors around them and the way in which certain political forces have aligned to shifting sensibilities allow the furthering and eventually the breakdown of a pro-tourism development regime to be unpacked. In more general terms, this analysis may hint at "overtourism" bringing forward political change in cities.

In Chapter 14, Sebastian Zenker pays attention to why and how pandemics might have an impact on a research agenda for urban tourism and urban tourism policy. Unquestionable, the current COVID-19 pandemic is one of the most impactful events of the 21st century and has also had tremendous effects on urban tourism. Since urban tourism is often associated with crowding and multiple shorter trips, it is especially vulnerable to health risks and is thus logically less attractive than more social-distance-friendly rural or coastal tourism. In addition, will the crisis probably have long-term effects on urban travel demand, travel supply and urban tourism policies? Therefore, the pandemic questions some of our basic assumptions, theories and our existing tourism research as such. Obviously, not all of our knowledge and foci will become obsolete, but this chapter questions some of our assumptions and discusses the evolving realities of the urban landscape in this regard. Thereby, the chapter in question gives some guidance to how a future post-pandemic urban tourism research agenda might look.

In Chapter 15, “Towards A Research Agenda for Urban Tourism: a synthesis", Jan van der Borg presents a plausible trajectory for future research into forms of urban tourism. This trajectory reflects the idea that tourism development might indeed be a powerful engine of development for cities and urban areas in general and art cities in particular if the right balance is struck between appreciating and promoting urban tourism, on the one hand, and conservation of the immaterial and material cultural goods uniquely possessed by them on the other. Only by embracing a development strategy that leads to sustainable urban tourism will the assets that form the foundations of urban tourism development be used optimally, and the various stakeholders - that is the local population, local entrepreneurs and visitors themselves - truly benefit from the opportunities that tourism offers them, also in the longer run. The current COVID-19 pandemic, which has disrupted tourism probably more than any other sector in the world particularly in the bigger cities, ought to be used to accelerate the process towards a new business model for urban tourism, in which quality is preferred to quality and the local population and local entrepreneurs play a central role. In this perspective, a new research agenda may very well lay a sound foundation for constructing such a new business model and supporting an innovative and visionary development strategy for urban 
tourism that might help eliminate a number of recurrent paradoxes in research and in policy that Ashworth and Page have written about in 2011.

\section{References}

Ashworth, G. and Page, S. (2011) Urban tourism research: recent progress and current paradoxes, Tourism Management, 32(1), 1-15.

Ashworth, G. and Voogd, H. (1990) Selling the City, Belhaven Press, London.

Bertocchi, D., Camatti, N., Giove, S. and van der Borg, J. (2020) Venice and overtourism: simulating sustainable development scenarios through a tourism carrying capacity model, Sustainability, 12(2), 512.

Boley, B., McGehee, N.G., Perdue, R. and Long, P. (2014) Empowerment and resident attitudes toward tourism: strengthening the theoretical foundation through a Weberian lens, Annals of Tourism Research, 49, 33-50.

Bolivar, M.P.R. and Meijer, A.J. (2016) Smart governance: using a literature review and empirical analysis to build a research model, Social Science Computer Review, 34(6), 673-692.

Cheshire, P.C. and Hay, D.G. (1989) Urban Problems in Western Europe, an Economic Analysis, Taylor \& Francis, London.

Costa, P., Gotti, G. and Van der Borg, J. (1996) Tourism in European heritage cities, Annals of Tourism Research, 23(2), 306-321.

Gorcheva, T. (2011) Measuring the internationalization of Bulgarian tourism and of 'Bulgaria' business destination, Tourism \& Management Studies, 1(1), 80-90.

Jansen-Verbeke, M. (1998) Tourismification of historical cities, Annals of Tourism Research, 25(3), 739-742.

Judd, D. and Fainstein, S. (1999) The Tourist City, Yale University Press, New Haven.

Law, C. (1993) Urban Tourism, Mansell, London.

Pine, N.J. and Gilmore, J.H. (1999) The Experience Economy, Harvard Business Press, Harvard.

Richards, G. and Wilson, J. (2006) Developing creativity in tourist experiences: a solution to the serial reproduction of culture? Tourism Management, 27(6), 1209-1223.

Troitiño Vinuesa, M.A. (1995) El Turismo en las Ciudades Históricas, Poliginas, 49-66.

UNWTO (2019) Overtourism? Understanding and Managing Urban Tourism Growth beyond Perceptions, Volume 2: Case Studies. UNWTO, Madrid.

Van den Berg, L. (1987) Urban Systems in a Dynamic Society, Gower, Aldershot.

Van den Berg, L., Van der Borg, J. and Van der Meer, J. (1995) Urban Tourism, Ashgate, Aldershot.

Van der Borg, J. (1991) Tourism and Urban Development, Thesis Publishers, Amsterdam. 
Jan van der Borg - 9781789907407 Downloaded from PubFactory at 04/26/2023 03:35:14PM via free access 